\title{
ADVANCED CONTROL STRATEGY FOR SINGLE-PHASE VOLTAGE-SOURCE ACTIVE RECTIFIER WITH LOW HARMONIC EMISSION
}

\author{
Vojtěch Blahník ${ }^{*}$ Z Zdeněk Peroutka ${ }^{* *}$ - Jakub Talla ${ }^{* *}$
}

\begin{abstract}
This paper introduces the advanced control of single-phase voltage-source active rectifier. This control provide direct control of trolley-wire current and active damping of low-frequency disturbances at the converter ac side. Our proposed control strategy combines PR controller with feed-forward model and low-frequency harmonic compensator based on resonant controllers. Achieved experimental results show excellent converter behavior, where converter is fed by strongly distorted supply voltage.
\end{abstract}

K e y w or d s: single-phase voltage-source, control strategy

\section{INTRODUCTION}

The single-phase voltage-source active rectifiers are utilized in many industrial systems, eg electric traction, active power filters, power factor controllers and photovoltaic converters. The power circuit of single-phase voltage-source active rectifier is composed of four IGBTs, input inductor and output capacitor (power circuit is shown in Fig. 1). This power converter allows the precise control of DC-link voltage $U_{c}$ to constant value and the current control on ac side of converter $i_{t}$ (the quality of flowing current is very dependent on selected control). Control of the active rectifier is a very popular issue and it is possible to find many interesting articles with different control methods: i) hysteresis control method [1,2], ii) model based control [3, 4], iii) vector control [5], iv) direct current control based on PR controller [6,7]. This type of power converter (H-bridge) is basic component for multilevel power converters [8-11] and especially for multilevel traction converter [12-14]. The main advantages of this control algorithm are satisfactory behaviour under steady-state conditions and very fast transient responses. On the other hand, this control algorithm does not compensate sufficiently the low-frequency harmonic distortion of the current on ac side of converter which is thus transferred to the trolley wire. This phenomenon is observable mainly under strongly distorted trolley wire voltage conditions. Therefore, the original control algorithm has been completed by a compensation block (socalled harmonic compensator) which compensates namely the $3 \mathrm{rd}, 5$ th and 7 th harmonic components of the current on ac side of converter. This paper describes in detail the enhanced control strategy and presents the simulations and experiments made on developed small-scale converter prototype.

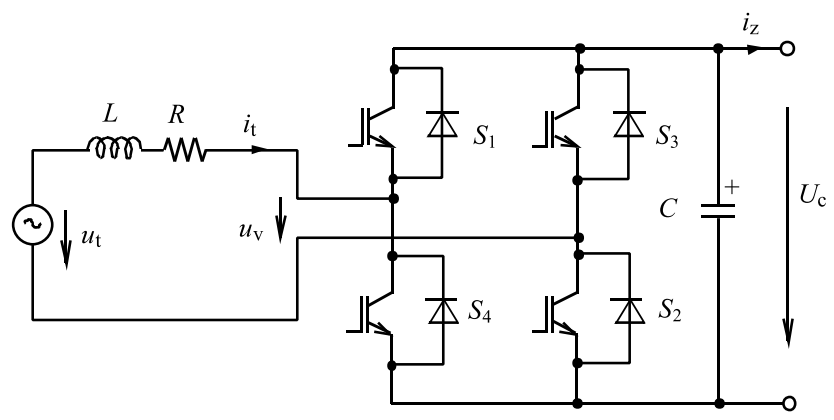

Fig. 1. Power circuit of voltage-source active rectifier

2 PROPOSED CONTROL OF VOLTAGE-SOURCE ACTIVE RECTIFIER

The proposed control of single-phase voltage-source active rectifier use PI controller for dc-link voltage control, PR controller for direct control of the fundamental harmonic of trolley wire current and resonant $(\mathrm{R})$ controllers for suppression of selected harmonics of trolleywire current. Proposed configuration of designed control is depicted in Fig. 2.

The dc-link voltage controller $\left(P I_{U_{c}}\right)$ commands the magnitude of required current $I_{m}$. From this value, a trolley-wire current command $i_{w}$ is calculated and compared with measured current $i_{t}$. A resulting error signal $e_{i}$ enters into a $\mathrm{PR}$ controller $\left(P R_{i_{t}}\right)$. This controller generates as its output a modulation signal $u_{\mathrm{v}_{-} \mathrm{PR}}$ which is summed in next step with both a feedforward term

\footnotetext{
* Department of Electromechanical Engineering and Power Electronics, Faculty of Electrical Engineering, lucke@kev.zcu.cz,

** Regional Innovation Centre for Electrical Engineering (RICE), Faculty of Electrical Engineering, University of West Bohemia, Univerzitní 26, 30614 Plzeň, Czech Republic, peroutka@ieee.org, talic@rice.zcu.cz
} 


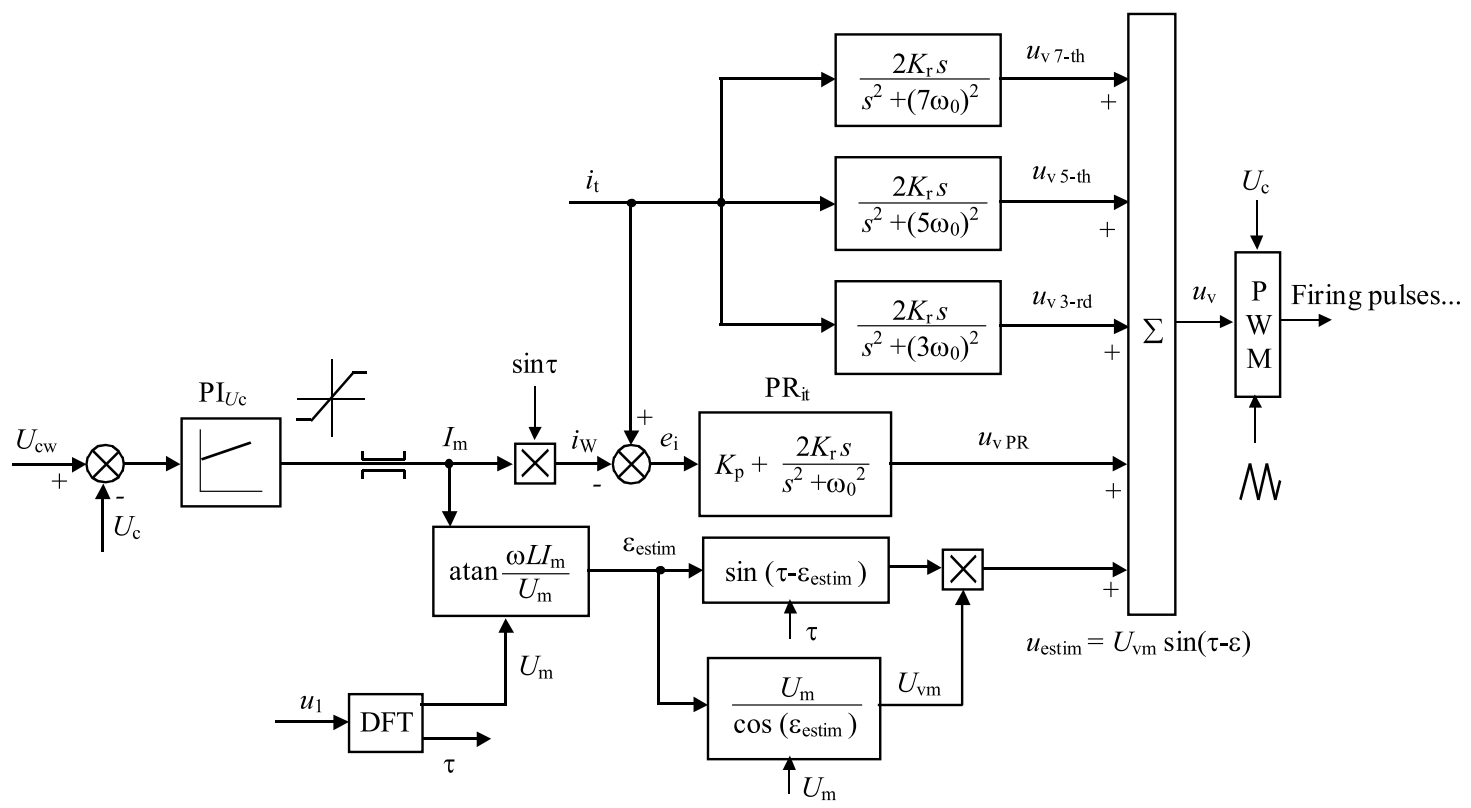

Fig. 2. Proposed control of voltage-source active rectifier

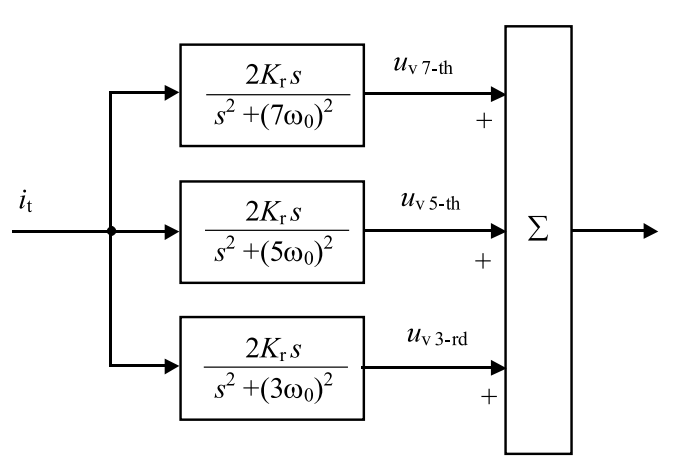

Fig. 3. Proposed low-frequency harmonic compensator reducing harmonic distortion of trolley-wire current

Table 1. Harmonic order contains in heavily distorted trolley-wire voltage

\begin{tabular}{|c|c|c|c|}
\hline $\begin{array}{l}\text { Harmonic } \\
\text { order }\end{array}$ & $\begin{array}{r}\text { Voltage } \\
\text { shape1 } \\
\mathrm{M}\end{array}$ & $\begin{array}{c}\text { Voltage } \\
\text { shape2 } \\
\text { gnitude }\end{array}$ & $\begin{array}{l}\text { Voltage } \\
\text { shape3 } \\
\% \text { ) }\end{array}$ \\
\hline basic ... (50Hz) & 100 & 100 & 100 \\
\hline $3 . \ldots(150 \mathrm{~Hz})$ & 20 & 20 & 17.72 \\
\hline $5 \ldots(250 \mathrm{~Hz})$ & 1.2 & 15 & 16.88 \\
\hline 7. ... $(350 \mathrm{~Hz})$ & 2 & 1 & 5.49 \\
\hline THDu & 40.27 & 50.04 & 50.16 \\
\hline
\end{tabular}

$u_{\text {v_estim }}$ estimated by a predictive model and the signals from harmonic compensator block which compensate low-frequency harmonic distortion of trolley wire current. In our case we use three resonant controllers with passfrequency of $150 \mathrm{~Hz}, 250 \mathrm{~Hz}$ and $350 \mathrm{~Hz}\left(3^{\text {rd }}, 5^{\text {th }}\right.$, and $7^{\text {th }}$ harmonic). Thus, the harmonic compensator block generates the signals $u_{\mathrm{v}_{-} 3 \mathrm{~h}}, u_{-} 5 \mathrm{~h}$, and $u_{\mathrm{v}_{-} 7 \mathrm{~h}}$. The resulting sum of $u_{\mathrm{v}_{-} \mathrm{PR}}, u_{\mathrm{v}_{-} \text {estim }}, u_{\mathrm{v}_{-} 3 \mathrm{~h}}, u_{v_{-} 5 \mathrm{~h}}$, and $u_{\mathrm{v}_{-} 7 \mathrm{~h}}$ represents the final modulation signal for PWM $\left(u_{\mathrm{v}}\right)$.

\section{COMPENSTAION OF LOW-FREQUENCY DISTURBANCES}

The main advantage of proposed control is using of harmonic compensator block. This block consists of three resonant controllers to compensate 3 -rd $(150 \mathrm{~Hz}), 5$-th $(250 \mathrm{~Hz})$, and 7 -th $(350 \mathrm{~Hz})$ harmonics. The input signal to the controllers is the current it, each resonant controller works as a filter for appropriate frequency. The output signals are subtracted from the modulation signal. It is a progressive compensation, because the resonant controller contains a double integration of (compensation rate is dependent on the selected gain $K_{r}$ ). The proposed low-frequency harmonic compensator is shown in detail in Fig. 3.

\section{EXPERIMENTAL RESULTS}

The converter control has been tested by simulations and after them implemented in the fixed-point digital signal processor Texas Instruments TMS320LF2812.

The highest benefit of the proposed control is shown in the converter behavior when fed by strongly distorted supply voltage. The proposed control provide the elimination of basic low-frequency disturbances produced directly by the converter. The dead-time and circuit nonlinearities caused further (higher harmonics) disturbances that are very difficult to compensate, especially for singlephase power converters.

Figures 4-9 present the experimental results of developed voltage-source active rectifier prototype under steady-state conditions. Converter loaded by $1 \mathrm{~kW}$, is fed by heavily distorted voltage, see channel 1 , in steadystate and rectifier mode, $f_{\text {switch }}=4 \mathrm{kHz}$. The main benefit of proposed control can be seen in Fig. 4, Fig. 6 and Fig. 8, where the compensated 3-rd to 7-th harmonics of 


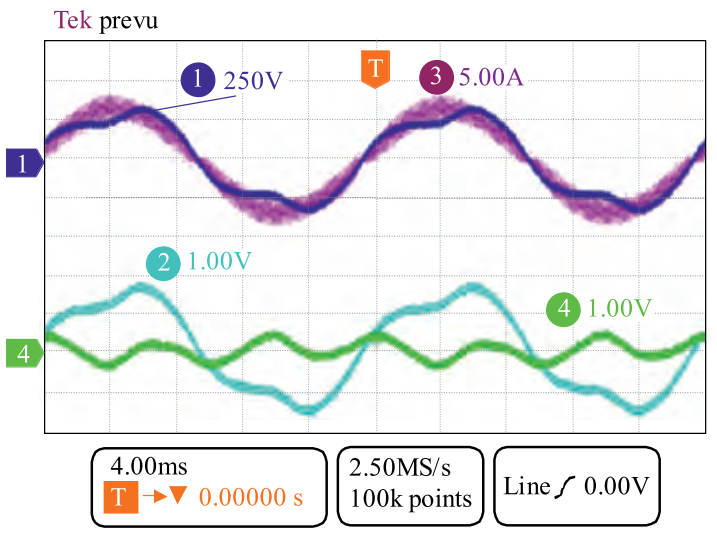

Fig. 4. ch-1 voltage harmonics: 1 -st $100 \%, 3$-rd $20 \%, 5$-th $1.2 \%$, 7 -th $2 \%$, ch- 4 : sum of compensation blok signals $(200 \mathrm{~V} /$ div $)$

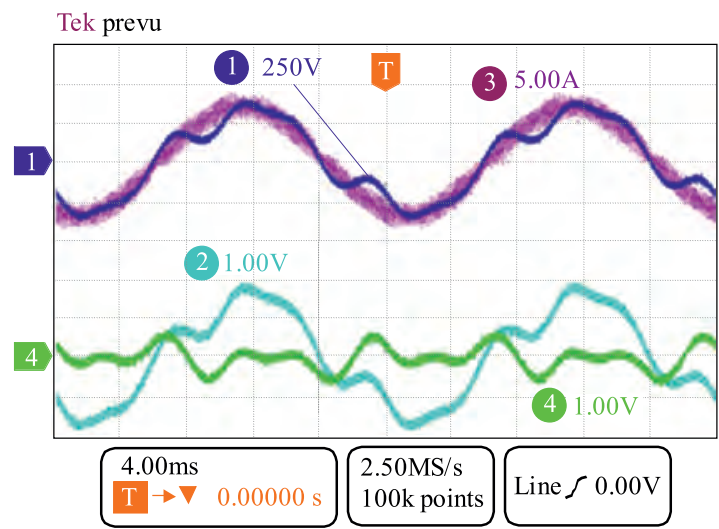

Fig. 6. ch-1 voltage harmonics: 1-st 100\%, 3-rd 20\%, 5-th 15\%, 7-th 1\%, ch4: sum of resonant control output signals $(200 \mathrm{~V} /$ div $)$

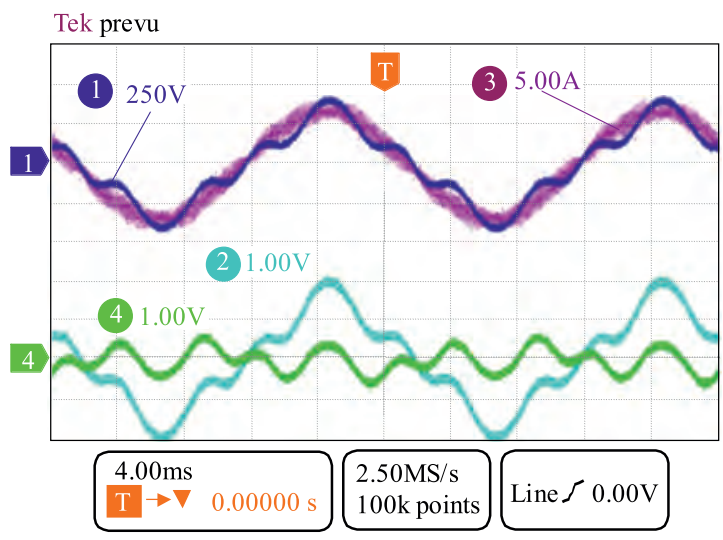

Fig. 8. ch-1 voltage harmonics: 1-st $100 \%, 3$-rd $17.72 \%$, 5-th $16.88 \%, 7$-th $5.49 \%$, ch4: sum of resonant control output signals $(200 \mathrm{~V} /$ div $)$

current, see channel 3, are shown, followed by the non compensated higher components (denoted by asterisk) that are approximately of same magnitude as the compensated ones. Channel 2 in Fig. 4, Fig. 6 and Fig. 8 is showing the control-modulation signal $u_{v}(200 \mathrm{~V} / \mathrm{div})$. The trolley-wire voltage is distorted by 3 -rd $(150 \mathrm{~Hz})$, 5 -th $(250 \mathrm{~Hz})$, and 7 -th $(350 \mathrm{~Hz})$ harmonics as listed in Table 1.

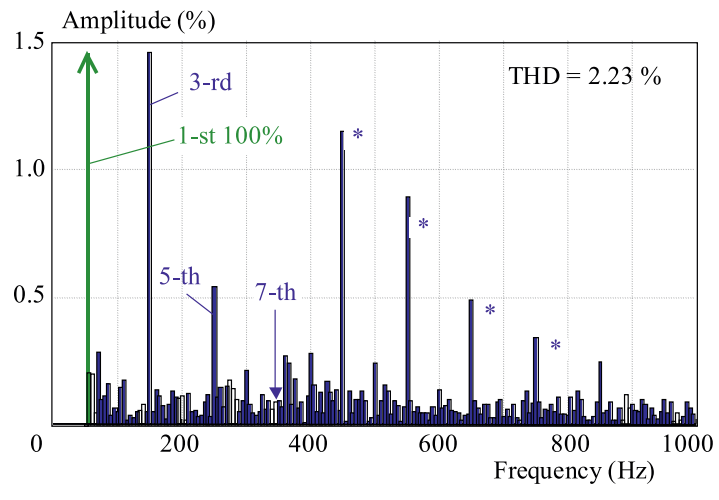

Fig. 5. Harmonic analysis and THDi of trolley-wire current, ch-3 in Fig. 4, fed by distorted voltage, ch-1 in Fig. 4

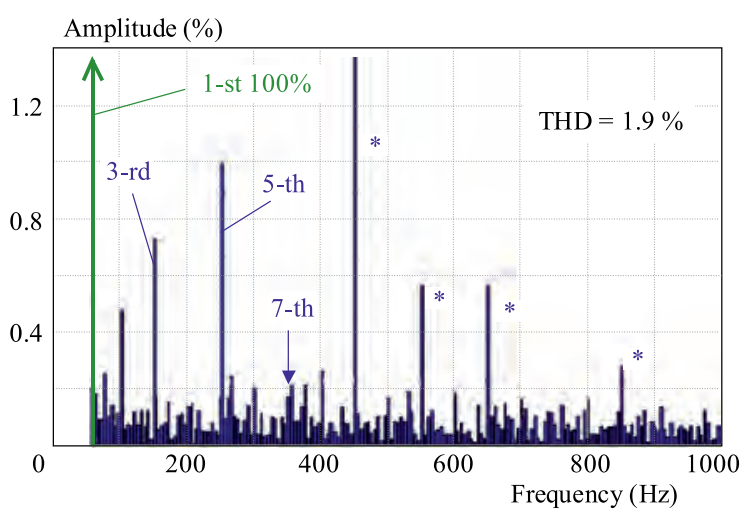

Fig. 7. Harmonic analysis and THDi of trolley-wire current, ch-3 in Fig. 6, fed by distorted voltage, ch-1 in Fig. 6

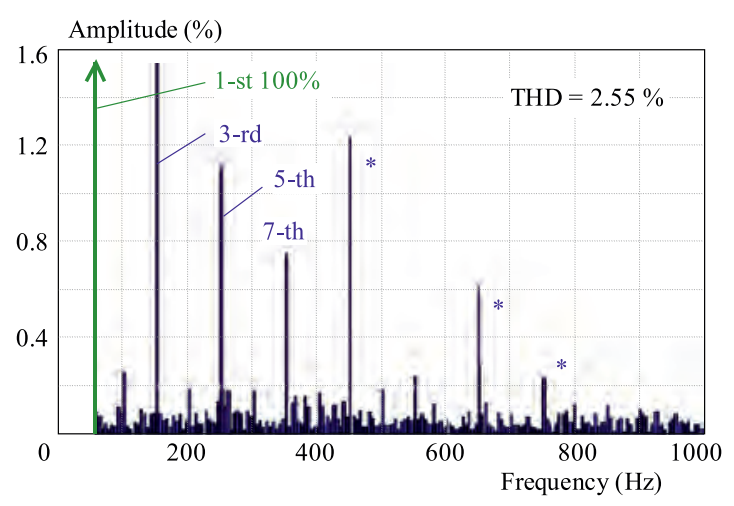

Fig. 9. Harmonic analysis and THDi of trolley-wire current, ch-3 in Fig. 8, fed by distorted voltage ch-1 in Fig. 8

\section{CONCLUSIONS}

- Proposed control strategy of single-phase voltagesource active rectifiers combines the model predictive feed-forward term with the PR controller of the fundamental harmonic of trolley-wire current.

- The direct control of the trolley wire current via PR controller enables a powerful limitation of the trolley wire 
current under hard transient conditions and also during the converter start-up.

- Due to used resonant controllers compensating 3th, 5 th, and 7th harmonics of the trolley wire current, we have achieved a significant reduction of the trolley wire distortion in low-frequency range

- The experimental results show excellent power converter behavior, even for converter fed by strongly distorted supply voltage

\section{Acknowledgment}

This research has been supported by the European Regional Development Fund and the Ministry of Education, Youth and Sports of the Czech Republic under project No. CZ.1.05/2.1.00/03.0094: Regional Innovation Centre for Electrical Engineering (RICE) and the Technology Agency of Czech Republic under project TA ČR TE01020038.

\section{REFERENCES}

[1] BUSOM, S.-MALESANI, L.-MATTAVELli, P.: Comparison of Current Control Techniques for Active Power Fillters, IEEE Trans. on Industrial Electronics 45 (1998).

[2] KOMRSKA, T.-ZAK, J.-OVASKA, S. J.-PEROUTKA, Z. : Current Reference Generator for $50-\mathrm{Hz}$ and $16.7-\mathrm{Hz}$ Shunt Active Power Filters, International Journal of Elektronics 97 (Jan 2010), 63-81.

[3] BLAHNIK, V.-PEROUTKA, Z.-MOLNAR, J.-MICHALIK, J.: AC/DC Converter for Traction Applications, In 2008 Applied Electronics, University of West Bohemia, Pilsen, 2008., pp. 13-16.

[4] HOLMES, D. G.-MARTIND. A.: Implementation of a Direct Digital Predictive Current Controller for Single and Three Phase Voltage Source Inverters, in Proc. IEEE IAS Annu. Meeting, 1996, pp. 906-913.

[5] RUFER, A.-BAHRANI, B.-KENZELMANN, S.-LOPES, L. : Vector Control of Single-Phase Voltage Source Converters based on Fictive Axis Emulation, ECCE 2009, pp. 2689-2695.

[6] HONG-SEOK SONG-KEIL, R.-MUTSCHLER, P.- - Van Der WEEM, J.-KWANGHEE NAM: Advanced Control Scheme for a Single-Phase PWM Rectifier in Traction Applications, Industry Applications Conference, vol. 3, 2003, pp. 1558-1565.

[7] GRMAN, L.-HRAŠKO, M.-KUCHTA, J.-BUDAY, J. : Single Phase PWM Rectifier in Traction Application, Journal of Electrical Engineering 62 No. 4 (2011), 206-212.

[8] KHATIR, M.-ZIDI, S. A.-HADJERI, S.-FELLAH, M. K.DAHOU, O.: Effect of the DC Control on Recovery from Commutation Failures in an HVDC Inverter Feeding a Weak ACNetwork, Journal of Electrical Engineering 58 (2007), 200-206.

[9] KHATIR, M.-ZIDI, S. A.-FELLAH, M. K.-HADJERI, S.-FLITTI, M. : The Impact Study of a Statcom on Commu- tation Failures in an hvdc Inverter Feeding a Weak ac System, Journal of Electrical Engineering 63 No. 2 (2012), 395-102.

[10] KATHALINGAM, S. R.-KARANTHARAJ, P.: Comparison of Multiple Carrier Disposition PWM Techniques Applied for Multi-Level Shunt Active Filter, Journal of Electrical Engineering 63 No. 4 (2012), 261-265.

[11] PERUMAL, M. P.-NANJUdAPAN, D.: Performance Enhancement of Embedded System based Multilevel Inverter using Genetic Algorithm, Journal of Electrical Engineering 62 No. 4 (2011), 190-197.

[12] DRABEK, P.-PEROUTKA, Z.-PITTERMANN, M.CEDL, M.: New Configuration of Traction Converter With Medium-Frequency Transformer using Matrix Converters, Industrial Electronics, IEEE Transactions on $\mathbf{5 8}$ No. 11 (Nov 2011), 5041-5048.

[13] DRABEK, P.-PITTERMAnN, M.-CEDL, M.: Primary Traction Converter for Multi-System Locomotives, Industrial Electronics (ISIE), 2010 IEEE International Symposium on, 4-7 July 2010, pp. 1010-1015.

14] DRABEK, P.-PITTERMAnN, M.-CEDL, M.: Novel Primary High Voltage Traction Converter Topology for Multi-System Locomotives, Energy Conversion Congress and Exposition ECCE 2009, IEEE, 20-24 Sep 2009, pp. 422-429.

Received 20 September 2012

Vojtěch Blahník (Ing, PhD) received the master and $\mathrm{PhD}$ degrees in Electrical Engineering from the University of West Bohemia, Plzeň, Czech Republic in 2006 and 2011, respectively. His research concerns power electronics, modern control methods of medium and higher-power converters.

Zdeněk Peroutka (Prof, Ing, PhD) received the MS and $\mathrm{PhD}$ degrees in electrical engineering from the University of West Bohemia (UWB), Pilsen, Czech Republic, in 2000 and 2004, respectively. Since March 2010, he has served as a ViceDean for Science and Strategy and deputy Dean of the Faculty of Electrical Engineering at UWB. Since October 2010, he has been a Scientific Director and Principal Investigator of the Regional Innovation Centre for Electrical Engineering which is a new research center at UWB. Since 2011, he has been a Professor at UWB. His research activities concern power electronics, electrical drives, and control theory. His main research topic is the control of drives of modern transport systems and vehicles. Power electronics converters for medium-voltage applications are the next important field of his research. His recent research activities are focused on sensorless control of ac motor drives.

Jakub Talla (Ing) received the MS degree in electrical engineering from the University of West Bohemia, Pilsen, Czech Republic, in 2006. Since 2006, he has been a PhD student in the Department of Electromechanics and Power Electronics, Faculty of Electrical Engineering, University of West Bohemia. His research activities concern power electronics, electrical drives, and control theory. His main research topic is the control of power electronics converters for medium-voltage applications. 